\title{
El amo castrado
}

\section{The castrated master}

\author{
Elisa Freijo Corbeira
}

Dirección General de Salud Pública de la Comunidad de Madrid

\begin{abstract}
Resumen
La propuesta de este texto es alejarse de las epistemes hegemónicas que subalternizan ciertos saberes en aras al conocimiento y aproximarse a epistemes otras, donde poder escuchar algo del eterno murmullo del afuera, de lo Real, algo de ese vacío que antecede y nuclea al sujeto. Epistemes disruptivas que no sirven al amo, que cuestionan las certezas y los consensos y nos aproximan al azar de la existencia, a la ambigüedad de la memoria y a la oscuridad de la noche. Epistemes como líneas de fuga por donde mirar al afuera, a ese ámbito abierto del ser desde donde es posible recuperar algo de lo singular de la existencia.
\end{abstract}

Palabras clave: castración, significantes amos, afuera, rizomórfico, fuga.

\begin{abstract}
The aim of this text is to walk away from hegemonic epistemes, that subordinate a certain wisdom for the sake of knowledge. It also tries to get closer to alternate epistemes, where we could be able to hear something of the eternal murmur of the outside, of the Real, something of that void that precedes and nucleates the subject. Disruptive epistemes that do not serve the master, that question the certainties and the consensus and get us closer to the random of existence, to the ambiguity of memory and the darkness of the night. Epistemes as escape lines to look outside, to the open realm of being from which it may be possible to recover something of the singularity of existence.
\end{abstract}

Key words: castration, master-signifiers, outside, rhizomorphic, fugue.

Recibido: 27-10-17. Aceptado: 19-1-18.

Elisa Freijo es Psicóloga y Técnica en prevención de adicciones de la Dirección General de Salud Pública de la Comunidad de Madrid.

Contacto: E. Freijo, elisafreijo@gmail.com

Cómo citar: Freijo, E. (2018). El amo castrado. Revista Stultifera, l (1), 30-44. ISSN 0719-983X

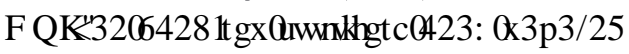




\section{EL AMO CASTRADO}

Arroja de tus brazos el vacío hacia los espacios que respiramos; tal vez los pájaros sientan el aire más amplio con su vuelo más íntimo.

Rainer María Rilke.

Cuando ya no nos queda nada, el vacío de no quedar podría ser al cabo inútil y perfecto.

José Ángel Valente.

Siempre tuvimos querencia, anhelo de un dios, de un amo, de un padre. Érase una vez un amo, nos cuenta Hesíodo en la Teogonía, Urano; un amo que habitaba en los cielos, pero tenía su falo anclado en la tierra, en Gea. Un amo que temía perder su poder en manos de su descendencia, por eso retenía a sus hijos en el seno de Gea. Gea talló una hoz de pedernal y se la entregó a sus hijos, la primera generación de los titanes, para liberarla de Urano. Fue el menor de los titanes, Cronos, quien castró a su padre mientras yacía con Gea y arrojó sus genitales a la tierra y el mar. De la sangre caída en la tierra surgieron los Gigantes, las Erinias y las Melias y en el mar, de la espuma y la sangre vertida, surgió Afrodita. Urano en castigo vaticinó que Cronos sería devorado por uno de sus hijos y así sucedió, Zeus, nieto de Urano, devoró a Cronos.

Erase otra vez un amo, un padre, el de la horda primitiva, que gozaba de todas las mujeres y tenía bajo su control a todos los hijos; estos se aliaron con las madres para derrocarlo, lo devoraron, introyectaron su poder y la culpa sobrevino, el lazo social, la regulación y la ley —la prohibición del incesto y de matar al padre-

Soñamos amos que todo lo tenían, sin castración, y teniéndolo todo o tal vez por eso fueron asesinados a manos de su descendencia. Cuentos fundantes, cuentos de amos, de dioses asesinados, al servicio de seguir alimentando la idea de completud y de unidad. Cuentos para ocultar que el amo, los amos siempre y desde el inicio estuvieron castrados. Soñamos amos, dioses para no tener noticias de la castración y mucho menos de ese vacío inaugural donde se alojará el sujeto. Pero dejemos de esconder la cabeza en la arena de las cosas celestes, pues los dioses, ya nos lo anunció Nietzsche, han muerto. También, siguiendo la estela nietzscheana, por la década de los sesenta del siglo pasado pensadores como 


\section{ELISA FREIJO CORBEIRA}

Foucault, Deleuze y Lacan se dejaron de cuentos y nos hablaron de otros amos: los discursos; discursos que como Cronos configuran la realidad y nos ordenan. Discursos que tratarán de dar cuenta del goce de aquel padre del mito de la horda primitiva. Discursos que como la sangre arrojada de los genitales de Urano y como el asesinato del padre de la horda, precipitarán el lazo social y darán sentido al sinsentido; pues debajo de cada discurso, debajo de la "función del muro", nos dirá Lacan, está el lugar de la verdad y el lugar del plus de goce, ese Real que estando fuera del sentido lo orienta y le da juego.

En el seminario 17, Lacan presenta sus cuadrípodos giratorios: cuatro discursos. De uno de ellos, el discurso del amo, heredero del legado hegeliano, nos dirá Lacan que es el hegemónico, pues "lo abarca todo incluso lo que se toma por una revolución en el sentido romántico" (Lacan, 1969-1970, p. 90); ordena el sentido y explica la realidad. Un discurso donde el saber (S2) trabaja al servicio del significante amo (S1). Esto sin duda nos recuerda a Foucault y su teoría del poder y el saber sobre la vida y su concepto de biopolítica como aquello que hace entrar la vida en el ámbito de los cálculos explícitos.

Discurso del amo, que nada quiere saber del azar ni de la fabulación. Discurso que diría Foucault está controlado, seleccionado y redistribuido por procedimientos que intentan conjurar poderes y peligros, que quiere dominar lo aleatorio y esquivar la materialidad. Discurso que gobierna y regula lo que es, como ese libro mallarmeano que explica el mundo, ese gran libro que codifica, que cuantifica nuestras tiradas de dados, extrayendo leyes y haciendo de ellas sucesos ordenados y predecibles. Discurso que se recorta sobre lo Real, que escribe en ese lugar vacío que precede al sujeto. Pero como Clara Janés, nos recuerda, nada detendrá lo que no es. Por más que el discurso del amo quiera dominar, controlar, cuantificar, hacer de los fragmentos unidad, vulnerar lo Real cambiante y detener el devenir; algo de ese Real, de eso que no es, escapa al discurso. Es ese resto, que Lacan denomina objeto "a", que cae del lado del sinsentido; resto que apunta a la causa de nuestro deseo. Resto que no es la parte que le falta a un todo, sino justamente aquello que hace a ese todo para siempre incompleto. Resto que no se puede estabilizar en ninguna significación, en ninguna identificación. Resto que podría desmontar al amo, ayudarnos a desidentificarnos de los significantes amos. Objeto "a" que recoge el susurro que las palabras dejan fuera para 


\section{EL AMO CASTRADO}

poder nombrar; objeto "a" que nos aproxima a ese vacío donde el amo escribió; objeto posibilitador de otras escrituras, de otros sujetos un poco menos sujetados.

Pero el amo insiste en su escritura. Bajo el imperativo a "seguir sabiendo" nos lanza a un saber - saber universitario- para no saber del inconsciente, para no ser; afirma Lacan: “donde sé no soy, donde no sé soy” (Lacan, 1969-1970, p. 109). Saber para taponar ese vacío, promesa de apertura del ser. En complicidad con el amo trabaja nuestra querencia a no saber, como escribe Hörderlin, "los mortales a diferencia de los Dioses y los poetas, oyen como aquellos que no pueden oír, su escucha es hacer oídos sordos y querer no oír”.

El saber del amo es el de la ciencia que nada quiere saber de la división del sujeto, haciéndonos creer que el sujeto es unívoco y uno, continuo y permanente. La verdad que esconde el discurso amo es la división, la incompletud y la inconsistencia del sujeto. La verdad del amo es que no sabe todo, es el esclavo el que sabe y sobre todo el amo no sabe nada de su deseo. Pero un verdadero amo no desea saber nada en absoluto, lo que desea es que la cosa marche.

El discurso del amo se sirve del discurso universitario para la producción de ese saber que excluya al sujeto dividido. Son los expertos los que articulan el discurso del amo y el universitario - diría Foucault — los que acumulan el conocimiento sobre los sujetos, bajo la premisa de que todo se puede saber, produciendo sujetos equivalentes, anónimos, mercancías, intercambiables, copias de los ideales propuestos por el amo. Esos "demasiados" nietzscheanos que son devorados, mascados y rumiados por el discurso del amo.

En Diferencia y Repetición, Deleuze (2002) sostiene que el sujeto no preexiste, no produce las representaciones que constituyen el mundo, sino que es producido por los juegos múltiples de lo real y la inmanencia; afirma que todas las identidades son simuladas, simulacros. Y es que el sujeto siempre es un lugar vacío, vacío que será capturado por los discursos, por los significantes (amos) a los que se identificará para decir que es quien le dicen que es. Significantes amos, tan fuera y tan dentro de ese vacío llamado sujeto.

En el arte y la estética japonesa la idea central es el vacío, los objetos no se agolpan unos sobre otros para taponarlo (horror vacui) sino que por el contrario se procura que dejen espacios, incluso en los hogares japoneses se horada en alguno de los muros un hueco para 


\section{ELISA FREIJO CORBEIRA}

dejar que algo del vacío se muestre y este espacio vacío, llamado Tokonoma, tendrá un lugar privilegiado para venir a ser ocupado por distintos objetos escogidos cuidadosamente que irán variando con el tiempo o para permanecer vacío. Vacío que diría Demócrito permite el movimiento, puro vacío evocador.

¿Cómo horadar en el muro del lenguaje?, en ese enjambre tramado de significantes que han tomado nuestra carne y nuestra piel, ¿cómo detener ese zumbido significante?, ¿cómo abrir, sacudirnos de alguno de esos significantes amos, para que algo del vacío se muestre? ¿Cómo crear un pequeño Tokonoma a salvo del poder y del saber del amo?

Los invitados en los hogares japoneses son colocados de espalda al Tokonoma de modo que quedan enmarcados en ese vacío para así destacar su presencia, algo que nos recuerda a la posición del analista, ese colocarse como objeto "a" —como vacío, Tokonoma, causa del deseo - para que así el sujeto se pueda mostrar. El discurso del analista al colocar en el lugar del agente la causa del deseo deja aparecer algo de la ausencia que habita en los significantes. El analista hace de semblante del objeto "a", algo parecido a eso "neutro" que tiende a suspender la estructura atribuida al lenguaje en relación con el ser, un lugar donde el discurso se desordena, lugar cercano al poema; lugar próximo al grado cero de la significación o al Igitur de Mallarmé. Lugares donde se lesionan las categorías de la metafísica occidental, los esquemas inmutables de la ciencia, los grandes relatos que aseguran y organizan lo que vemos y lo que decimos, esos regímenes de enunciabilidad y de visibilidad de los que hablaba Foucault.

Pero tenemos sed de sentido, un terco afán de unidad y completud, nada queremos saber de vacío, falta, castración, de lo que no es, de lo que no está. Como escribe A. Pizarnik: "Y qué sé yo qué ha de ser de mí si nada rima con nada" (Pizarnik, 2004, p. 248). De las fisuras y desgarraduras hacemos rostros, manos, formas, presencias para nuestra sed y así alejamos la ausencia que nos atraviesa. Presencias, certezas efímeras, como ese "nido de nubes" de Leandro Erlich, donde las nubes etéreas, mutables, inconsistentes y de formas fantasmales son encerradas en vitrinas, representando en su forma mapas de distintos países, conjugando así la cartografía con la incertidumbre, mostrando la fragilidad de las formas, de las fronteras. Fragilidad como la de ese calco yoico, ese légamo de mandatos e ideales que constriñe nuestro ser. 


\section{EL AMO CASTRADO}

Todos estamos embarcados en el discurso de la ciencia. Siguiendo a Foucault podríamos decir que el soberano - el poder- se ha escondido bajo el saber de la ciencia, bajo las disciplinas; un soberano despótico que si hace falta aparecerá. Discurso de la ciencia, discurso universitario que trabaja para el amo, marcando fronteras, poniendo límites, dando forma, organizando, produciendo un saber que borra cualquier disonancia ontológica, un saber de lo ente y no de lo óntico. Un saber, que Lacan denomina "todo saber", que opaca la causa del deseo, pues solo en lo incompleto podemos localizar algo de lo que falta. S2, saber disciplinario dice Foucault, que trabaja al servicio del amo, para homogeneizar, normalizar y eliminar cualquier línea de fuga por donde pueda aparecer la división del sujeto y, por tanto, la pregunta por otro saber no sabido que es el saber del inconsciente. Un saber disjunto al saber del amo, extraño al discurso de la ciencia, pero que se impondrá a la ciencia como un hecho pues como Lacan dice:

el discurso del inconsciente corresponde a algo que depende de la institución del propio discurso del amo; o, dicho de otro modo: el discurso del amo es el discurso del inconsciente a tal punto que podríamos pensar que no hay inconsciente sin amo. (Lacan, 1960-1970, p. 95)

Escribe C. Lispector: "Sí. Pero lo sé todo, todo lo que sé sin realmente saber no tiene sinónimo en el mundo del habla, pero me enriquece y me justifica. Aunque perdí la palabra porque intenté decirla" (Lispector, 1999, p.55). Este saber sin realmente saber no tiene ninguna relación con ese saber del amo, con la producción de conocimiento. El saber es el goce del Otro y lo que conduce al saber nos dice Lacan (1969-1970) "no es el deseo de saber sino el discurso de la histérica" (Lacan, 1969-1970, p. 22), próximo a lo que Foucault denominó la creación de pensamiento. El discurso de la histeria hará surgir la verdad escondida en el discurso del amo: la incompletud, la inconsistencia, la división del sujeto ( $\mathrm{S}$ barrado) y la colocará en el lugar del agente.

Lacan, en "El amo castrado", recurre a Dora porque la histeria siempre interroga al amo, lo denuncia. El sujeto histérico ofrece su división al amo para que éste le proporcione un saber, pero como ya sabemos un verdadero amo no quiere saber nada del saber no sabido, de modo que el saber del amo no alcanza a responder a su pregunta, pues lo que la histeria quiere saber es la verdad sobre la causa de su deseo y solo el discurso analítico puede responder a esto poniendo en el lugar del agente la causa del deseo, haciendo el analista de semblante del objeto "a". 


\section{ELISA FREIJO CORBEIRA}

El discurso de la histeria con su pregunta dirigida al amo, con su querer saber quiebra la certezas, hace tartamudear al amo, rompe con la verdad del amo, con las coordenadas de la mismidad — como hacía Lyotard con sus paralogías, esas nuevas jugadas que al entrar en contradicción con las reglas establecidas obliga al sistema a desplazar sus límites provocando la diseminación del sentido- pues la pregunta de la histeria es una pregunta, no por la significación, sino por el sentido y esta misma pregunta alberga en su interior lo que el sentido debe al sinsentido y apunta directamente al vacío de ser.

Discurso de la histeria que muestra que la producción de conocimiento es un hecho político que responde a intereses e intenciones concretas, estableciéndose epistemes hegemónicas que subalternizan ciertos saberes en aras al conocimiento. Pero hay epistemes otras, disruptivas, donde podemos escuchar algo del eterno murmullo del afuera, de lo Real, algo de ese vacío que antecede y nuclea al sujeto; epistemes que no sirven al orden lógico racionalista de la mathesis universal cartesiana, que no sirven al amo, que cuestionan las certezas y los consensos y nos aproximan al azar de la existencia, a la ambigüedad de la memoria y a la oscuridad de la noche.

¿Son posibles otras escrituras, otras inscripciones en los legajos de vacío que no llegaron a ser colonizados por el discurso del amo? Otras escrituras libres de prejuicios y preconcepciones, con palabras que aligeren la pesadez significante, que no se dobleguen ante los significantes amos; palabras que digan, evoquen y se abran paso por la angostura de los significantes amos. Escrituras donde resuene entre el fragor significante, entre aquellas flores y guirnaldas que recubrían el carro de Dioniso, algo del silencio, de la pérdida, alguna bocanada de vacío.

¿Es posible pensar la existencia como potencia, abierta a la multiplicidad de caminos, y no como una esencia, un dato ya dado que tan solo hay que actualizar? ¿Es posible dejar de ser estrellas apagadas, yoes que obstinadamente siguen en la órbita del amo ajenos a la inutilidad de sus esfuerzos? ¿Es posible abandonar los rebaños de ovejas somnolientas y ser un poco, dionisiacos, luminosos como aquellas luciérnagas pasolinianas?

Apostamos por ser un poco rizomorfos, distanciarnos de esos grises árboles, esos sistemas arborescentes jerárquicos, organizados en torno a una unidad superior que copiamos (Deleuze, 1977). Distanciarnos de los discursos — sistemas arborescentes- que nos 


\section{EL AMO CASTRADO}

preexisten, nos determinan, nos igualan, nos constriñen y nos silencian; dejar de hacer calcos y atrevernos a experimentar, explorar y trazar mapas.

El discurso del amo y el universitario trabajan para que las diferencias y singularidades se acomoden a sus imperativos. Los significantes amos signan nuestras vidas, marcan y determinan nuestra existencia, operan a modo de esencias bajo las que las diferencias se pierden a favor de un yo a imagen y semejanza de la propuesta amo. Existencias, pues, realizadas, actualizadas continuamente repitiendo esa esencia, modelo del amo. Giorgio Agamben, frente a estas vidas ya vividas, realizadas, vidas anónimas e intercambiables propone la vida como potencia, confrontada a la imposibilidad, abierta a la multitud de caminos, propone la "forma-de-vida" como un modo en el que cabe la pluralidad de la vida, de yoes que nunca coinciden consigo mismo, sino que viven como "rostros", como seres expuestos para los cuales lo impropio es constitutivo de lo propio (Agamben, 2010); forma-de-vida que requiere, en palabras de Nietzsche, "desaprender a andar y hablar y echar a volar por los aires bailando" (Nietzsche, 1979, pp. 44-45).

Desaprender la lengua del amo, esa lengua encrática, apagada, gris que todo lo uniforma e iniciar pequeños vuelos. Nos advierte Barthes que el lenguaje encrático, lenguaje de repetición, no solo es de la clase que está en el poder, sino que es un discurso difuso, expandido, osmótico que impregna todos los intercambios sociales; un discurso saturado, en el que no hay lugar para el otro ni para uno mismo.

La propuesta del discurso analítico es hacer de la lengua una lengua de semillas, germinal; algo parecido a tensar la lengua para que suene, para que diga con un decir otro, para que hable más y menos de la cuenta. Volvernos nómadas y extranjeros en nuestra propia lengua, para dejar de hablar y comenzar a decir, desaromar las palabras mediante otras palabras, desviar los significantes. Atender a eso que se cuela entre los significantes, eso que Beckett denominó "lo innombrable", eso que en su aparecer entraña la violencia de lo aprehensible lingüísticamente y que, sin embargo, solo el lenguaje puede hacerlo aparecer. Todo se dice y todo puede ser dicho en torno a eso innombrable, eso que clama por ser nominado; pero decirlo equivale a decir nada a perderlo; pero solo en este decirlo se aparece como presencia, una presencia efímera. Innombrable, como ese vacío que aloja al sujeto, fructífero vacío que llama, que grita desde el silencio. El sujeto, como el haiku, es algo que 


\section{ELISA FREIJO CORBEIRA}

ocurre fuera de la lengua, pero sin embargo necesita de la lengua para surgir. Sujeto y haiku como wu-shi, como forma de salir de la interpretación. El susurro del haiku dice: eso es todo, como el inicio de un cuento: "erase una vez un conejo que no hacía otra cosa sino ser conejo". ¿Será posible pensar en un sujeto que no haga otra cosa que ser sujeto?

Volvamos a los dioses. Ahora será Hermes, hijo de Zeus y de una ninfa, heraldo de los dioses, dios del lenguaje, simboliza la piedra de toque del sentido, nos ayuda marcando las rutas del sentido; Hermes ese mensajero de los dioses apolíneos, dioses del orden, de la armonía de la buena forma. Pero Hermes es también portador del falo de la fecundidad dionisíaca; en su caduceo, en esa vara mágica con la que cierra y abre los ojos a los mortales, se abrazan las serpientes que simbolizan la tierra y las alas celestes. Hermes, esa serpiente alada, portador del lenguaje, de los significantes; Hermes que tanto nos recuerda Zaratustra, a ese bailarín ligero dispuesto a volar, ese que nos hace señas con las alas, ese que sabe del arraigo a la tierra, de las serpientes y también del andar ligeros. Pero a veces Hermes se enreda en las serpientes, olvida los cielos azules, sus alas cesan, sus vuelos se detienen y sus palabras dejan de elevarse por encima de la significación, cargan con significados caliginosos, pétreos, totalizadores, que no dejan ningún espacio al sentido y mucho menos al sinsentido. La arena de las palabras convertida en piedra. Significantes que se significan a sí mismos, como ocurre en el campo de la ciencia, atentando a la función del significante que todo puede significarlo salvo a sí mismo. Bajo esta forma Hermes se despide de las alturas, de las posibilidades y trabaja para el discurso del amo, ese discurso performativo en el sentido de que construye la realidad bajo significantes cerrados y totalizadores. Discurso que funciona al modo althusseriano como una interpelación, esa operación que nos propone un modelo de identificación. Significantes que nos separan de lo real de los objetos. Significantes a los que nos identificamos para ordenar lo caótico, lo azaroso, el sinsentido, para hacer de lo Real orden, relato, realidad; una realidad a nuestra medida o más bien a la medida del Amo.

Significante amos, ojos ciclópeos, totalizadores, que nos signan; cadenas de significantes para amarrarnos, fijarnos y hacernos creer que somos uno mismo, el mismo, que somos yo. Cordadas significantes, discursos para hacer del cuerpo un cuerpo organizado, para dar unidad a los fragmentos, continuidad y consistencia a la materia, para detener el 


\section{EL AMO CASTRADO}

vacío que grita desde el silencio. Pero no hay interpelación ni enunciado performativo ni significante amo en que se inscriba la materia evanescente de la vida, que recubra totalmente al sujeto, siempre queda un resto sin simbolizar. No hay significación definitiva para el sujeto por eso adviene el sentido y de nuevo Hermes y sus alas haciéndonos señas para conducirnos a ese vacío, Lichtung heideggeriano, condición de posibilidad de lo que aparece; vacío donde la claridad y la luz juegan en el tiempo del aparecer; vacío como ese desierto y su secreta desolación sin nombre al que nos aproximamos en un vértigo dulce y abismal.

Decimos con Heidegger que el sujeto no es una constancia social sino una apertura problemática, dehiscencia que se abre con el discurso de la histeria. No somos, por más que el saber del amo se empeñe, tan solo sujetos epistemológicos o cognoscentes. Por más que el discurso universitario quiera agotar todo nuestro ser y colonizar nuestro fecundo vacío con su saber ciego y opaco al deseo, lo abierto, el afuera nos llama desde esos huecos que dejan las palabras al decirse, esos huecos por los que respiramos. Y si los huecos están saturados de palabras tendremos que abrirlos, como dice Beckett (2004): "mi propia lengua cada vez se me antoja más un velo que ha de rasgarse para acceder a las cosas o a la nada que hay atrás". Pero como no es posible eliminar la lengua de golpe y porrazo habrá que abrir en ella un agujero tras otro hasta que lo que acecha detrás sea algo, sea nada, comience a rezumar y a filtrarse. Beckett (2004) se pregunta: “¿Existe alguna razón por la cual la terrible materialidad de la superficie que encostra la palabra no se preste su disolución?” (p. 4).

Y de nuevo con Heidegger decimos que es en el ámbito de lo abierto donde ha de hacerse la pregunta por la existencia, por las existencias. Eso abierto a lo que no podemos aproximarnos más que por hendiduras, como esa noche de la que habla el poeta, por los intersticios, por los rincones de la boca, por los silencios, por los pliegues de la piel, rasgando velos y blancas sábanas. Frente al saber del amo, el imperialismo de la certeza, las identidades de raíz única y el sujeto clausurado; mirar a lo abierto supone saber de la incompletud, de la insuficiencia de la cadena significante para nombrarnos, para decirnos, saber de la separación radical entre la palabra y la vida. Mirar al afuera supone empezar a trazar una ontología del inacabamiento, abrirnos a la multiplicidad del sentido ese que va más allá de la significación que escapa el cálculo y a la ciencia. 


\section{ELISA FREIJO CORBEIRA}

Pero ¿cómo soltarnos, desenredarnos las serpientes?, ¿cómo dejar de ser camellos porteadores servidores de ídolos e ideales del Amo, superfluos monos trepadores y fanáticos de la verdad del saber del amo?, ¿cómo ocupar posiciones móviles y desvinculaciones apasionadas?, ¿cómo salir de las identificaciones de los significantes amos, de las certezas y la clausura de las significaciones del saber de la ciencia?, ¿ cómo invertir el platonismo, pues no son los significantes amos la esencia del sujeto? Tal vez, podríamos salir, desenredándonos, buscando un enredo más afín a nuestro ser; descolgándonos, desidentificándonos de los significantes amos, a la búsqueda de otros significantes más atinentes a nuestro ser. Desenredarse es una operación parecida al "exilio" del que habla Jean Luc Nancy, entendiendo la existencia como exilio, pero no como un movimiento fuera de algo propio a lo que se regresaría, sino el exilio como la dimensión misma de lo propio. La posibilidad de encontrar lo más propio, algo del ser en ese exiliarse, en ese desidentificarse de los significantes amos. Exilio como apertura y salida donde encontrar una morada un asilo, ásylos, ese lugar que no puede ser atrapado, que no puede convertirse en botín del discurso del amo; siendo así el exilio, un asilo, un lugar donde el sujeto está al abrigo.

Cómo despojarse de las palabras mayores, palabras encráticas y buscarse en las palabras menores; podríamos decir en las palabras acráticas, esas que no se disuelven en discurso oficial, esas que recogen los despojos, los restos que el discurso del amo dejó a su paso. Palabras menores donde cabe lo singular y la diferencia. Tal vez empezando a pensar la diferencia en sí misma, y la relación de lo diferente con lo diferente, independientemente de las formas establecidas de la representación que llevan las diferencias a lo mismo y las hacen pasar por lo negativo.

Desidentificarse, buscar en lo familiar su radical alteridad, en lo cotidiano las huellas de su extrañeza. Quizá eso desconocido extraño se pone en juego cuando dice Barthes (2007) "lo que puedo nombrar no puede realmente punzarme. La incapacidad de nombrar es un buen síntoma de trastorno" (p. 100). Y de nuevo, lo innombrable.

Desidentificarse de los significantes amos, algo parecido a lo que hace Tapiés en su pintura utilizando signos — cruces, aspas — que van más allá de los significantes, signos que conllevan notas cosmogónicas en clave ambigua y extraordinariamente abierta. Desidentificarse no es borrarse sino re-conocer, desmarcarse, tomar distancia y ampliar la 


\section{EL AMO CASTRADO}

mirada dentro de la pluralidad de los significantes a otros significantes. Es desplazar, descentrar, fracturar esos significantes que nos ordenan; salir de lo uno, de ser lo otro de lo mismo; saber del carácter histórico y heterogéneo de todas las identidades; salir de lo universal como rector del mundo, como única forma de mirar el mundo y aproximarse a lo pluri-versal. Desidentificarse recuerda a la propuesta deleuziana de ser rizomorfos. Deleuze y Guattari (2004), afirman:

Ser rizomorfo es producir tallos y filamentos que parecen raíces, o, todavía mejor, que se conectan con ellas al penetrar en el tronco, sin perjuicio de hacer que sirvan para nuevos usos extraños. Estamos cansados del árbol. No debemos seguir creyendo en los árboles, en las raíces o en las raicillas, nos han hecho sufrir demasiado. Toda la cultura arborescente está basada en ellos, desde la biología hasta la lingüística. No hay nada más bello, más amoroso, más político que los tallos subterráneos y las raíces aéreas, la adventicia y el rizoma. El pensamiento no es arborescente, el cerebro no es una materia enraizada ni ramificada. (p. 20)

Desidentificarnos de los significantes amos también nos recuerda a esas zonas temporalmente autónomas de las que hablo Hakim Bey. Zonas — de tierra de tiempo, de subjetividad, de imaginación - liberadas de los requerimientos del Estado, del amo, del saber de la ciencia; áreas que se autodisuelven para reconstruirse en cualquier otro lugar o tiempo antes de que el sistema las capte, las incorpore. Zonas siempre inestables, precarias que escapan a los ojos de Argos. Inestabilidad como la del discurso analítico, siempre amenazado por el discurso universitario, que solo se da en la experiencia psicoanalítica y en algunos momentos sociales donde se produce algo del orden del "acontecimiento".

De la mirada de aquel cíclope, de aquel único ojo que Bentham nos mostró, ahora asistimos a la de un cíclope de miles de ojos; que nos miran, nos vigilan, nos controlan. Ojos guardianes para guardarnos de nosotros mismos; guardianes al servicio de Hera, aquella diosa portadora de las cápsulas de amapola, de esas narcóticas granadas de olvido, de sangre y muerte; guardianes que nunca descansan, ojos siempre abiertos.

Ojos, miradas del amo que bajo la ciencia y la tecnología cobran múltiples y proteicas formas. No son ojos desinteresados, sus miradas son intrusivas, performativas. Miradas impúdicas, limpias, que quieren sujetos transparentes, como aquellas ratas recreadas en el laboratorio de la Universidad de Hiroshima de piel transparente. Basta con mirar, sin intervenir para ver dentro y fuera. Amo y ciencia colaboran estrechamente arrojando luz, una luz cegadora para todo ver. Visibilidad total, todos presentes, presentables, sin pliegues, sin 


\section{ELISA FREIJO CORBEIRA}

rincones donde anide la oscuridad, sin intimidad. Todos dispuestos y expuestos a la mirada, a los discursos amo y universitario. Ver para prever, como esas zonas de las ratas que se iluminan cuando empiezan a desarrollar un cáncer. Bajo la transparencia y la homogeneidad, pareciese que nada quedase de la pulsión escópica, del deseo, del secreto, del silencio, de la pasión, de lo imposible. Todo cae bajo la tiranía de la visibilidad y en este paroxismo lumínico más que nunca nos parece necesario cerrar los párpados para ver, liberar a nuestros ojos de las trampas como decía Rilke. Nuestros ojos van secándose, perdiendo su mirar, su color, su parpadeo aproximándose a máquinas ópticas; abandonando su mirar en otros ojos: cámaras, televisores, móviles, webcam. En el extremo, ser hombres transparentes con nuestras corneas cosidas a las pantallas.

¿Cómo escapar de la mirada de Argos Panoptes, el fiel sirviente de Hera? Hermes lo hizo, tomó la apariencia de un inofensivo pastorcillo, un pastorcillo "menor" diría Deleuze, y se presentó ante Argos tañendo su flauta, Argos bajó la guardia y sus múltiples ojos se cerraron por un rato. El arte, la música y la creación como modalidades de fuga; escapar de Argos haciendo de nuestra existencia una obra de arte afirmativa y abierta al mundo, que diría Foucault, creando modos de existencia capaces de resistirse al poder que quiere apropiárselas y de hurtarse al saber que quiere penetrarlas.

Frente al saber del Amo, frente a su visibilidad total y su esencialismo óntico; pongamos bajo sospecha lo que vemos, como hizo Magritte, y lo que decimos, como hicieron Rousell o Brisset. Apostemos por una ontología del inacabamiento donde no se trata de ser dueños, autores, de escribir en la página en blanco mito de la modernidad, sino de inacabar lo acabado, deshacerlo por sus márgenes, desaturarlo, pues como dice Chillida (2005): "Todas las cosas se hacen importantes en los bordes, en los límites, fuera, cuando las cosas dejan de ser" (p. 58). Busquemos las líneas de fuga por donde mirar al afuera, a ese ámbito abierto del ser desde donde es posible recuperar algo de lo singular de la existencia. Iniciemos un viaje como el propuesto por Caproni (2012): "Mi viaje ha sido/quedarme donde estoy/Adonde nunca fui” (p. 137). Un viaje a donde nunca fuimos, porque siempre estuvimos, aunque velado por los significantes amos. 


\section{EL AMO CASTRADO}

\section{Referencias}

Agamben, G. (1995). Homo sacer. El poder soberano y la nuda vida. Valencia, España: PreTextos.

Agamben, G. (2010). Medios sin fin. Notas sobre la política., Valencia, España: Pre-Textos.

Agamben, G. (2005). Lo abierto. El hombre y el animal. Valencia, España: Pre-textos.

Barthes, R. (2007). La cámara lúcida. Barcelona, España: Paidós.

Beckett, S. (2006). El innombrable. Madrid, España: Alianza.

Beckett, S. (2004). Deseos del hombre. La carta alemana. Segovia, España: La Uña Rota.

Butler, J. (2001). Mecanismos psíquicos del poder. Madrid, España: Cátedra.

Caproni, G. (2012). Poesía escogida. Valencia, España: Pre-Textos.

Chillida, E. (2005). Escritos. Madrid, España: La Fábrica.

Deleuze, G., \& Guattari, F. (2004). Mil mesetas, Capitalismo y esquizofrenia. Valencia, España: Pre-Textos.

Deleuze, G. \& Guattari, F. (1977). Rizoma: Introducción. Valencia, España: Pre-Textos.

Deleuze, G. (2002). Diferencia y Repetición. Buenos Aires, Argentina: Amorrortu.

De Ori, J. (2014). Chillida, el desocupador del espacio. Revista Escritura e imagen, 10 (especial), 366-371.

Foucault, M. (1991). Estrategias de poder. Obras esenciales, (Vol. 2). Barcelona, España: Paidós.

Janés, C. (1979). Antología personal (1959-1979). Madrid, España: Rialp.

Janés, C. (1981). Eros. Madrid, España: Hiperión.

Lacan, J. (1988). Seminario 7, La ética del psicoanálisis. Buenos Aires, Argentina: Paidós.

Lacan, J. (1969-1970). Seminario 17, El Reverso del psicoanálisis. Buenos Aires, Argentina: Paidós. 


\section{ELISA FREIJO CORBEIRA}

Lispector, C. (1999). Un soplo de vida, pulsaciones. Madrid, España: Siruela.

Lispector, C. (2002). Cuentos reunidos. Madrid, España: Alfaguara.

Nancy, J. (1996). La experiencia de la libertad. Barcelona, España: Paidós.

Mallarmé, S. (1925). Igitur, ou la Folie d'Elbehnon. Paris, Francia: Gallimard.

Nancy, J. (2002). Un pensamiento finito. Barcelona: Anthropos.

Nancy, J. (2003a). Corpus. Madrid, España: Arena.

Nietzsche, F. (2001). Así habló Zaratustra. Madrid, España: Alianza editorial.

Nietzsche, F. (1979). El Nacimiento de la Tragedia. Madrid, España: Alianza editorial

Nietzsche, F. (2001). El Nacimiento de la Tragedia. Recuperado de http://www.maraserrano.com/MS/articulos/nietzsche1_elnacimientotragedia.pdf

Pizarnik, A. (2004). Poesía completa. Barcelona, España: Lumen. 


\section{REVISTA STVLTIFERA DE HUMANIDADES Y CIENCIAS SOCIALES}

\section{VOLUMEN 1, NÚMERO 1, PRIMER SEMESTRE DEL 2018}

ISSN 0719-983X

\section{Artículos de Humanidades y Ciencias Sociales}

La violencia como espectáculo.

Juan Carlos Pérez Jiménez

El amo castrado.

Elisa Freijo Corbeira

España, una meditación política: Cataluña y Euskadi.

Mikel Aramburu Zudaire

Del saber sabio al saber dramatizado. Nuevos fundamentos para la aplicación permanente del teatro en el aula.

Luis Fernando Lara Coronado

Ontotecnia, ingeniería organizacional y actores emergentes.

Alejandro Ochoa Arias y Juan Antonio González de Requena Farré

\section{Reseñas}

Memoria Visual de Legua Emergencia, vida y oficio de Mario Alarcón.

Pedro Pablo Achondo Moya

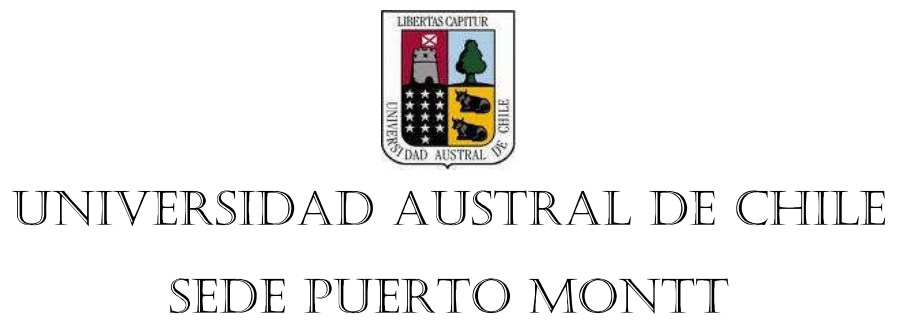

